\title{
Syllabic Keyboard: A Literacy Game for Motivating First Grade Children to Read
}

\author{
Fabrício Guerra $^{1}$, Flavius Gorgônio ${ }^{1}$, Dalton Guerrero ${ }^{2}$, Jorge de Figueiredo ${ }^{2}$ \\ ${ }^{1}$ Departamento de Computação e Tecnologia (DCT) \\ Universidade Federal do Rio Grande do Norte (UFRN) - Caicó(RN) - Brazil \\ ${ }^{2}$ Departmento de Sistemas e Computação (DSC) \\ Universidade Federal de Campina Grande (UFCG) - Campina Grande(PB) - Brazil \\ \{fabricio,flavius\}@dct.ufrn.br, \{dalton, abrantes\}@dsc.ufcg.edu.br
}

\begin{abstract}
The main purpose of this work was to conduct an experiment with a proposed technological solution - Syllabic Keyboard - in order to verify if it could impact on reading motivation related metrics in Brazilian disadvantaged $1^{\text {st }}$ grade children, for their literacy issues are harmful to their general school success possibilities and motivation to read have been found to be associated with good reading achievements in further grades. Results from experimental data analysis showed positive effects from gameplay on reading motivation, taste for reading and playing experience.
\end{abstract}

\section{Introduction}

Literacy deficits, in Brazil, have been such a problematic issue that they can be easily described in numbers and probabilities. A recent PISA report [OECD 2017] for the country, for instance, shows, among its key findings, that "one in two students performs below Level 2 [out of 6!] in reading, more than twice the OECD average", "only 1.4 percent of students in Brazil are top performers in reading, significantly below OECD average (8.3 percent)" and "socioeconomically disadvantaged students in Brazil are less likely to succeed at school than their more advantaged peers". Furthermore, the report also compares its current results with data from former reports, showing that "reading performance in Brazil has remained unchanged since 2000" - that is, our low reading scores have remained statistically unchanged ever since the report was first published, almost two decades ago.

Literacy issues, however, are not exclusive to Brazil and they have been addressed, as well, by researchers worldwide, different factors being found to be positively related to reading comprehension achievement. Becker et al. [Becker et al. 2010], for instance, reported an important association between early reading motivation and later literacy skills and taste for reading, while taste for reading, back in a Brazilian context, was cited by 5-10 years-old children as a major factor for them to actually read books [Failla 2012].

In the face of literacy related studies and given Brazilian discouraging context, a suite of different mobile games, commonly referred to as z-Reader games [Guerra et al. 2018], was developed and successfully improved $2^{\text {nd }}$ and $3^{\text {rd }}$ grade children reading skills and book reading frequency. The application, however, did not address children in $1^{\text {st }}$ grade, at the beginning of Brazilian alphabetizing cycle, nor reported reading motivation or playing experience claims. 
VIII Congresso Brasileiro de Informática na Educação (CBIE 2019)

Anais do XXX Simpósio Brasileiro de Informática na Educação (SBIE 2019)

In this work, we introduce Syllabic Keyboard games (or simply SKey games), a mobile application developed as an extension of the z-Reader application that suits regular $1^{\text {st }}$ graders reading possibilities and serves both as a bridge from $1^{\text {st }}$ graders to common z-Reader games for $2^{\text {nd }}$ grade as well as simpler games for struggling $2^{\text {nd }}$ grade readers.

Under all these considerations, SKey games were subject to an experiment in order to answer the following research questions:

(RQ1): Does playing SKey games positively change $1^{\text {st }}$ grade children's motivation towards reading?

(RQ2): Does playing SKey games provide a good experience for $1^{\text {st }}$ grade children, improving their taste for reading?

\section{SKey Games and Its Theoretical Foundation}

z-Reader is an Android application consisting of implementations of literacy games that work on $2^{\text {nd }}$ and $3^{\text {rd }}$ graders. These games, however, involve reading narrative texts and, for that reason, do not suit the profile of children in $1^{\text {st }}$ grade, children who have just entered Brazilian alphabetizing cycle and, hence, did not yet acquire enough reading skills for properly decoding and understanding narrative texts.

We now introduce the SKey game design, which is primarily directed to children with poor reading skills and fluency - typical cases including common $1^{\text {st }}$ grade students. In general, SKey games consist of setting up words, syllable by syllable, with the help of a talking keyboard that has syllables, instead of letters, as keys. Each to-be-assembled word has a video animation representation and the sequence of all videos forms a cartoon to be dubbed. In that sense, in a serious game perspective [Deterding et al. 2011], the reward associated to SKey is the same as any original z-Reader game: the possibility of producing a self-dubbed cartoon. After one finishes setting up all the concerned words, hence, SKey games move to an original z-Reader Record Room session for user to record his/her voice over characters and actions. This cartoon construction process also brings together some general theoretical influences present in original application, like Constructivism [Müller et al. 2009] and Constructionism [Papert and Harel 1991]: interactions always have a close relation to an educational subject of study (reading) and the whole gameplay always involves the conscious construction of a public entities - the words, the cartoon itself.

Examples of user interfaces for a particular SKey implementation are depicted in Fig. 1. At each case, there is a video area at the center, a initially empty text field for word visualization, just below the video area, and several key buttons, all labeled with syllables - the syllabic keyboard itself. A backspace button, just beside the word visualization text field complements the user interface elements for SKey games.

The first action made by eventual player is single touching the video area. The touch causes a word pronunciation in the mobile device audio system - in this particular case, PROVOCAR, Portuguese word for "to provoke" or "to insult", would be pronounced. While the word is being pronounced, a corresponding video animation is played in the video component. The word pronounced is called target-word. After listening to its pronunciation, one must complete the task of writing the target-word by dragging, in the right order, its syllables from the keyboard into the word visualization text field. At 


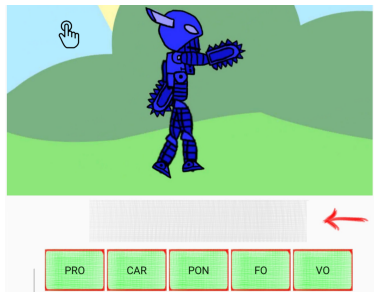

(a) Action and target-word

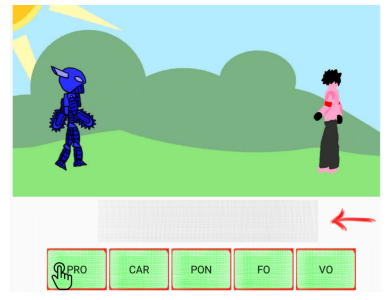

(b) Syllable pronunciation

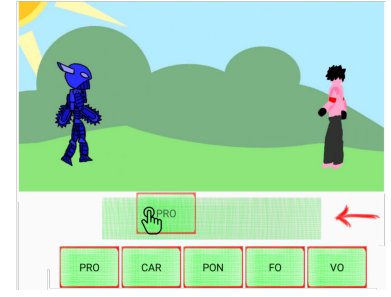

(c) Syllable drag

Figure 1. SKey user interface examples

each drop, the dropped syllable is added to the end of the current word in the text field. Syllable sequence presented is random and a single touch on a syllable causes its pronunciation in the same way it is pronounced in the target-word as well as a single touch on the word text field causes the pronunciation of the currently written word. A single touch on the backspace button causes the last syllable dropped in the text field to be erased. The task is correctly completed if touches in video area and in the text field cause the same pronunciation and, after that, the game moves to another target-word. When the last word is entered, the game moves to a Record Room session for voicing over all the video pieces showed during gameplay. Figure 1 depicts the actions of seeing an animation while listening to the target-word Figure 1(a), triggering syllable pronunciation Figure 1(b) and dragging the correct syllable Figure 1(c). Touched screen points involved in each example were depicted as a hand icon in the images.

Each animation piece played in the video area is meant to drag child's attention [Hong et al. 2004] as well as to provide pictorial description for the target-word. This part of SKey game design was inspired by Mayer's well known Cognitive Therory of Multimedia Learning (CTML[Mayer 2005]). In a CTML perspective, this interaction is meant to help children with some of the theory's core processes. Notably, the selection of relevant words is straight forward, since only one word is pronounced, and this oneword-only pronunciation is intended to support the process of selecting relevant images animation effects like zooming or focusing may also guide this latter process. In addition, the process of integration of verbal/pictorial content with prior knowledge is supported. It's expected that video animation will always trigger prior knowledge schema retrieval, because characters will always be visually doing something children are very likely to have been seeing within the context of their own experiences in real life or with other video contents: characters will walk, run, fly, fall, fight, kick, talk, curse, make gestures etc. So, even in the case in which the child does not know what the pronounced word mean, he/she will have some prior knowledge to integrate with verbal/pictorial content. In brief, this interaction alone, still not considering the keyboard part, is meant to either improve or reinforce child's vocabulary. It is important that the animation playing and word pronunciation occur simultaneously once both external verbal and pictorial content must be activated in children's working memory for integration to be performed [Horz and Schnotz 2010].

Finally, the second part of SKey game design - the word set up or the keyboard - deals with single word decoding, having a special focus on how this process works for the beginner reader - that is, with a special focus on phonological rules for translating 
VIII Congresso Brasileiro de Informática na Educação (CBIE 2019)

Anais do XXX Simpósio Brasileiro de Informática na Educação (SBIE 2019)

grapheme to sound. These rules, however, are taken at a syllable granularity rather than at a letter granularity. This feature reduces the cognitive demands of the task, once using letters would explode the number of possible sequence options and, from a Cognitive Load Theory[Sweller 1994] perspective, increase extraneous cognitive loads and negatively affect the underlying learning purpose. For a 3-syllables-6-letters word - quite a common case for Portuguese language - children would have to deal with a total of 720 permutation possibilities and, worse, letters alone would have poor relation to the sounds listened from the word pronunciation, forcing them to guess a possible solution. The syllables in SKey are to be pronounced as they are in the word context exactly to avoid guessing and to foster sound/grapheme comparisons and associations.

\section{Materials and Method}

An experiment was conducted in order to make possible to answer the research questions enumerated in Section 1 by empirically testing the treatment - SKey games - defined in Section 2 and a sample of $\mathrm{N}=25$ participants were available for this experiment. Participants were volunteer disadvantaged $1{ }^{\text {st }}$ Grade children studying at the same public school, all of them joining the study with proper formal parental consent. They were at a regular age/grade situation and had no diagnosed cognitive problems.

Children were randomly assigned either to a control group that attended regular computer lab classes (conducted by school teachers), either to an experimental group that attended SKey sessions, in which children played the games in pairs. Game sessions were played in Android 5.0.2 Samsung Galaxy Tab 4 tablets. Tablet processors were quadcores $1.2 \mathrm{GHz}$, screen sizes were 10.1 inches and screen resolutions were $1280 \mathrm{x} 800$ pixels. Inner SKey cartoon animation stories were common fairy tales, fables and child narratives, and children assembled an average of 12 1-to-4 syllable words per gameplay.

The dependent variables observed in the experiment concerned objective measures of paper book reading and subjective assessment of experimental group children's opinion centered at their experience with the application. These opinions assessed by means of a 5-scale Likert questionnaire about enjoyment to play, enjoyment to play in pairs, potential frequency of playing and taste for reading - detailed item descriptions are provided in the next section.

The assessment of the paper book reading count variable was performed by school professionals with all due precautions to confirm that children effectively read the books at home - children had to perform informal presentations, in class, involving their comprehension of the narratives, so the books could be counted as read. The assessment of children's perceptions involving the experiment, as well as SKey sessions, was conducted by the research team and with the help of a pedagogical support team gently provided by partners in our university.

Note that children in $1^{\text {st }}$ grade are not supposed to actually read a child book on their own, for they are still beginning the alphabetizing cycle and struggling to master the rules of decoding graphemes into sounds. Thus, the paper book reading variable represents rather their attitude and motivation of borrowing a book at school library, taking it home to read with the help of their parents and properly presenting the book story in class. For the sake of simplicity, we will refer to this motivational variable, along the text, as just "paper reading", but reader must be aware that the term represents and 
quantifies the just mentioned attitudes. The process of counting paper book reading was part of a regular school program, so children do not associated it with our research nor the researchers took any part in this process. Program extent was synchronized with experiment execution extent so eventual variation on book count in experimental group could be associated with experimental treatment.

Children were also pre-tested for phonological awareness, with TCFO [Seabra and Capovilla 2013], a test that was found to be "the best predictor of reading skills [that $1^{\text {st }}$ graders should have] at the end of $2^{\text {nd }}$ grade" [Dias et al. 2013]. Our intention was not to compare the pre-test results with a post-test (TCFO is an oral test, with no reading involved), but to check if phonological awareness differences in groups could explain potential book reading variation rather than the experimental treatment itself. We summarize all the information concerned in this discussion with the experimental setup in Table 1, showing dependent variables, their values/assessments and sample size descriptors.

Table 1. A summary of the experimental setup

\begin{tabular}{l|c|c|c|c}
$\begin{array}{l}\text { Dependent } \\
\text { variable }\end{array}$ & \multicolumn{2}{|c|}{ Sample size } & \multicolumn{2}{c}{ Value } \\
\hline Cont & Exp & Initial & Final \\
\hline Paper book reading & 13 & 12 & 0 & number of books read \\
\hline Phonological awareness & 13 & 12 & TCFO (pre-test) & - \\
\hline $\begin{array}{l}\text { Opinions on playing games } \\
\text { and reading }\end{array}$ & - & 12 & - & questionnaire answers \\
& & & &
\end{tabular}

\subsection{Game sessions procedure}

Two training sessions and eight regular weekly sessions were scheduled with children from experimental group. Regular sessions consisted of children playing SKey games in pairs, interacting freely with game features with as little intervention from the research team as possible. Nevertheless, children could ask for help if they didn't find out how to perform a given game task.

The instructions for playing in pairs, explained in training sessions, were the following: both children should listen to the target-word and one of them was responsible for dragging the syllables. The other child could help but without interacting with the game. At each target-word, the process was the same, just alternating the roles of the children the one who had interacted with the game would help, the one who had previously helped would interact. After assembling all target-words, children were free to record the cartoons as they pleased. This passivity from researchers towards children was important for we wanted any observed variation to be associated primarily with SKey gameplay. Any interactive, elaborated pedagogical approach would eventually mix its own effects on observed variables with SKey effects, besides potentially leading to affective bias in questionnaire responses.

\section{Results or How We Answered Research Questions}

The analysis of paper book reading count was based on the following approach. Initially, the dispersion of the variable, for both groups, was visually observed in notched box plots. Then, as visual clues indicated differences between groups, we proceeded to distribution 


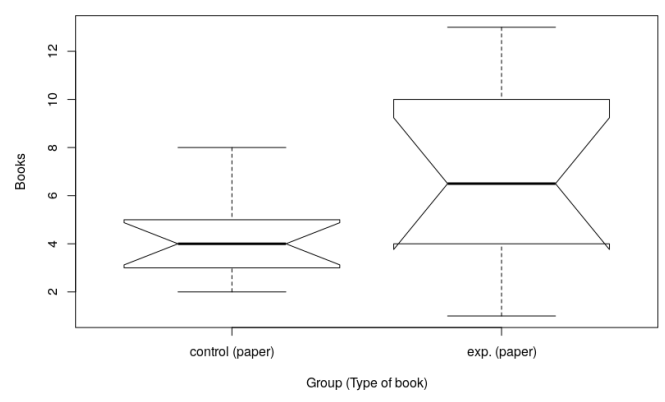

(a) Distribution of paper reading

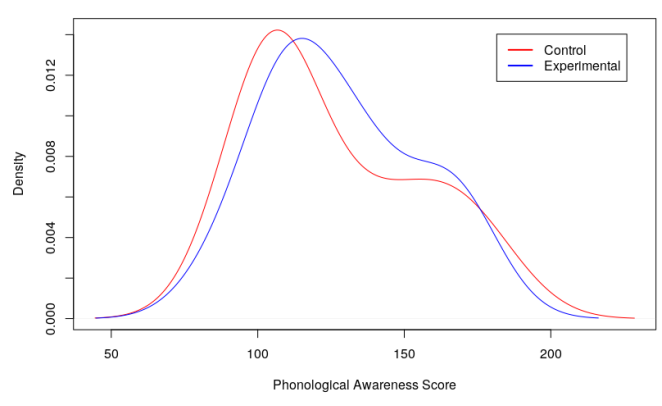

(b) Density of phonological awareness

Figure 2. Plots for observed variables

checking and inferential comparisons. Shapiro-Wilk test was used to check for normality in density distributions, a pre-condition for parametric tests. Once these tests indicated acceptance of normality distributions for both experimental and control groups, a parametric Welch two sample t-test was used to investigate inferential differences between them. Finally, as differences were found in favor of experimental group, the effect size was calculated by means of Cohen's d procedure.

For playing experience and literacy related subjective items assessment, our observations regarded enjoyment, group playing, will to read and potential playing frequency. These variables were assessed by means of a 5-scale Likert questionnaire. Children's responses were visually analyzed by a percentage bars plot depicting negative, neutral and positive attitudes towards each item. All item evaluations were way above neutral response.

\subsection{Paper book reading count}

Our hypothesis was that the SKey games positively impacts on the number of paper books the students read. The notched box plots in Figure 2(a) show distributions for this variable considering control and experimental groups.

There is an intersection between the confidence intervals (denoted by the notches) of both plots, but the median for exp. (paper) is slightly above the confidence interval top limit for control (paper). This is an informal evidence that children in experimental group read more paper books than children in control group. In addition, average paper book reading in experimental group was 6.91, reasonably greater than average paper book reading in control group, which was $\mathbf{4 . 4 6 .}$

One could argue that these numbers may be explained by differences in phonological awareness between groups before the children had access to the treatment. However, density plots depicted in Figure 2(b) show distributions of the pre-test for this variable in both groups and there seems to be no statistical differences between Control and Experimental with regards to Phonological Awareness Score - so this is another evidence that greater paper book reading in experimental group is associated primarily with experimental treatment.

Given the visual clues, we proceeded with inferential test for paper book reading across groups, which was significant, so we rejected the hypothesis that average book 
VIII Congresso Brasileiro de Informática na Educação (CBIE 2019)

Anais do XXX Simpósio Brasileiro de Informática na Educação (SBIE 2019)

reading was equal across groups in favor of the alternative hypothesis that average paper book reading in experimental group was greater than it was in control group. Table 2 summarizes all concerned null hypothesis, including extra comparison between phonological awareness scores, statistical tests and effect size in order to confirm the results just discussed and visually depicted in Figure 2(a) and Figure 2(b). The tests confirm previous visual analysis that associates SKey playing with the behavior of reading more paper books. The magnitude of this impact is measured as Cohen's $\mathrm{d}$ and indicates a medium effect size value of 0.77 .

\begin{tabular}{l|c|c|c|c} 
Null hypothesis & $\begin{array}{c}\text { Normality } \\
\text { test p-value }\end{array}$ & \multicolumn{2}{|c|}{$\begin{array}{c}\text { Hypothesis test p-value } \\
\text { Welch }\end{array}$} & $\begin{array}{c}\text { Cohen's } \\
\text { Wilcox }\end{array}$ \\
\hline $\begin{array}{l}\text { control (phon. awareness) }= \\
\text { experimental (phon. awareness) }\end{array}$ & $0.054-0.55$ & 0.425 & 0.321 & - \\
\hline control (paper) = exp. (paper) & $0.07-0.49$ & $<\mathbf{0 . 0 3 5}$ & - & 0.77
\end{tabular}

Table 2. A summary of phonological awareness statistical tests

Thus, as we are taking paper book reading as an expression of reading motivation, as discussed earlier, the test results answer RQ1, that is, SKey games positively changes First grade children's motivation towards reading.

\subsection{Opinions on playing and reading}

The Likert scale questionnaire used to assess these variables considered the common 5 options, from strongly disagree to strongly agree, for the analysis. The items presented to experimental group children were the following:

(Item-1): I enjoyed playing the games.

(Item-2): I prefer to play the games with another child.

(Item-3): Playing the games improved my taste for reading.

(Item-4): I would like to play the games for the whole year.

Since we were dealing with 6-years-old children, they responded the form with emoji-coded faces (two sad emoji faces meaning strongly disagree and so forth) and after training similar sentences for each item. One actual questionnaire item was read to children only after they covered all 5 possibilities with similar training items. "I enjoyed playing the games" was trained with sentences like "I enjoyed playing soccer", "I enjoyed doing my math homework" etc.

One can visualize children's judgments for the proposed items as proportions inside the sample, as depicted in Figure 3. The left side of the plot concerns disapproval and only Item-2 had negative evaluations (strongly disagree and disagree) - a total of $\mathbf{1 8 \%}$, against $\mathbf{8 2 \%}$ of positive answers (agree and strongly agree). Also, none of the items had neutral answers (0\% all along the items, labeled in the middle of the plot) and 3 items had 100\% approval, 1 of which, Item-4 (potential frequency of use), spited between agree and strongly agree but with more than $90 \%$ of strongly agree. Finally, 2 items, the ones concerning enjoyment (Item-1) and taste for reading (Item-3) were evaluated with 100\% of strongly agree, which are remarkable results, specially the latter, which stands as an important observation by itself and also helps to explain the results observed for paper book reading, reinforcing the claim that the games caused the variation earlier detected 
VIII Congresso Brasileiro de Informática na Educação (CBIE 2019)

Anais do XXX Simpósio Brasileiro de Informática na Educação (SBIE 2019)

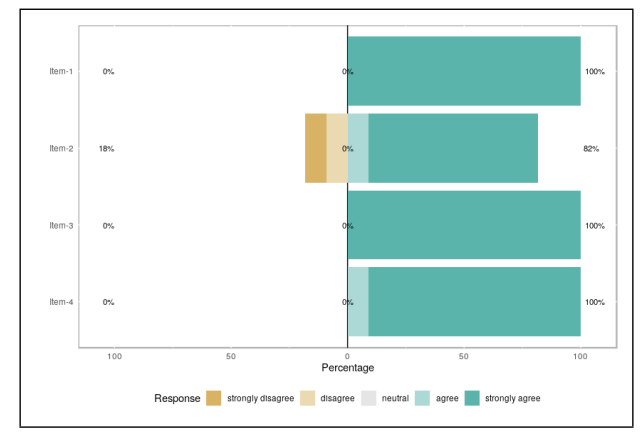

Figure 3. Questionnaire items proportions

by inferential tests regarding that variable and, in consequence, reinforcing the claim that the games positively affected children's motivation to read.

This way, following questionnaire results, we also consider answered RQ2, that is, playing SKey games provided a good experience for First grade children, improving their taste for reading.

\section{Discussion}

The most expressive result from the above described experiment was probably the one about reading motivation, expressed as paper book reading and taste for reading. Because we've found quite a lot of researches pointing out that reading motivation (intrinsic motivation, as in our case) was positively associated with reading abilities, including a huge cross cultural cross language literature review [Schiefele et al. 2012] and a longitudinal study [Becker et al. 2010]. Given the importance of this variable, as attested in these works, we expected some solutions trying to impact on it, even though the authors identified association and bidirectional relations, not cause. Sadly, we did not find any ordinary software or mobile application that reported metrics and effect sizes for motivation and changes associated to some technological treatment. Deitos et al. [Deitos et al. 2018], for instance, did a pretty good job with a successful application for children writing training. They reported improving motivation in children but it regarded the motivation to play the (writing) game again - which, of course, is a great achievement but is a different variable, for we observed reading motivation in general, in paper books, regardless of any technology. We believe that most researchers often try to impact on more measurable variables like reading comprehension, or reading behavior (time spent reading, reading frequency etc.) like original $z$-Reader itself. We are not stating that no technological solutions impacted on reading motivation. Probably several did. But researchers did not report hypothesis testing with corresponding effect sizes, so our discussion about that important topic is a bit limited.

On its turn, the evaluation of some sort of user experience with software, when it comes to literacy related software for children in early grades, does not also seem to be a topic that researchers are giving the importance it deserves. Among a couple of systematic mappings considered in our study [Gaspar et al. 2015, Takacs et al. 2015], for instance, user experience evaluation was not taken as observable variable in any of them, possibly due to the lack of researches that reported it in the first place. A more recent and more specific review centered at literacy technology for children [León et al. 2017] - a mobile 
VIII Congresso Brasileiro de Informática na Educação (CBIE 2019)

Anais do XXX Simpósio Brasileiro de Informática na Educação (SBIE 2019)

application review, not a systematic mapping - also does not mention any software experience consideration. There are, nevertheless, researches that evaluated user experience by more general means than ours. Manero et al. [Manero et al. 2015], for instance, developed somewhat successful games to increase high school students' interest in theater and measured their experience by one 7-option question about "experience evaluation" but their work was not literacy centered and was not for children in early grades as well. So, assessing children's impressions with regards to their experience with playing SKey games was as important in that sense of reporting this kind of data for this public, as it was for the explicit results.

Conducting SKey sessions with children playing in pairs was, honestly, a decision based in funding problems, since we just did not have enough tablets for all children. The high acceptance of this particular item is important for reducing eventual implementation costs. This is particularly important if we look at the statistics described in PISA report [OECD 2017], briefly discussed back in Section 1. If our low reading scores are stable for nearly 20 years, probably good technological solutions provided by researchers along the way were not widely adopted, and, in that sense, implantation costs may have been an issue. With that in mind, this incidental "pair playing" turned out to be good choice, since the results and further perspectives turned out to be positive.

\section{Conclusions}

In this paper we presented SKey, a literacy mobile game design, and investigated the impacts of its use through an empirical study with $1^{\text {st }}$ grade children of a Brazilian public school. Preliminary results indicated a significant association between SKey gameplay and the increase of motivational and playing experience metrics. In addition, children's opinions on their participation in the experiment suggests that the mobile application can also contribute to increase their taste for reading. Despite these results, there are some limitations to account for. Our sample is small and not representative of intended population, as we are investigating problems in the context of such a huge population as Brazilian $1^{\text {st }}$ grade disadvantaged children. This is even worse if we consider general $1^{\text {st }}$ grade children. So the results, even notably positive, must be regarded with caution and should give place to further studies, specially studies that replicate the experiment executed in this work in similar contexts. Note that, given that literacy problems cross the whole country, working on a representative sample will hardly will be achieved by any researcher, so experiment replication in different contexts stand as a practical way of reinforcing our results. Finally, we believe that SKey games may be easily integrated in or used with z-Reader suite, complementing the original games and opening the possibility of an integrated application that covers all three grades of alphabetizing cycle with empirically tested results for all of them - the whole set of mobile games, thus, improving reading motivation, reading comprehension and reading frequency.

\section{References}

Becker, M., McElvany, N., and Kortenbruck, M. (2010). Intrinsic and extrinsic reading motivation as predictors of reading literacy: A longitudinal study. Journal of Educational Psychology, 102(4):773.

Deitos, F., Franco, M., and Peres, A. (2018). Ditado digital: um jogo para auxílio da escrita no ensino fundamental. In Brazilian Symposium on Computers in Education. 
VIII Congresso Brasileiro de Informática na Educação (CBIE 2019)

Anais do XXX Simpósio Brasileiro de Informática na Educação (SBIE 2019)

Deterding, S., Khaled, R. N., and Nacke, L. (2011). Gamification: Toward a definition. In CHI 2011 Gamification Workshop Proceedings.

Dias, N. M., Perez, C., Macedo, E. C. d., Seabra, A. G., and Duarte (2013). Evidências de validade e fidedignidade da prova de consciência fonológica por produção oral. In Avaliação Neuropsicológica Cognitiva, chapter 11. São Paulo: Memnon.

Failla, Z. (2012). Retratos da leitura no Brasil 4. Imprensa Oficial Estado de São Paulo.

Gaspar, W., Oliveira, E., and Oliveira, K. (2015). Aprendizagem da língua portuguesa com dispositivos móveis: Um mapeamento sistemático da literatura. In Brazilian Symposium on Computers in Education, volume 26, page 140.

Guerra, F., Santos, J. A., Serey, D., and de Figueiredo, J. C. A. (2018). z-reader: a mobile game suite for improving children's reading skills and behavior. In Brazilian Symposium on Computers in Education, volume 29, page 565.

Hong, W., Thong, J. Y., and Tam, K. Y. (2004). Does animation attract online users' attention? the effects of flash on information search performance and perceptions. Information Systems Research, 15(1):60-86.

Horz, H. and Schnotz, W. (2010). Cognitive load in learning with multiple representations. In Cognitive load theory, pages 229-252. Cambridge University Press, NY.

León, A. M., Bravo, C. B., and Fernández, A. R. (2017). Review of android and ios tablet apps in spanish to improve reading and writing skills of children with dyslexia. Procedia-Social and Behavioral Sciences, 237:1383-1389.

Manero, B., Torrente, J., Serrano, Á., Martínez-Ortiz, I., and Fernández-Manjón, B. (2015). Can educational video games increase high school students' interest in theatre? Computers \& Education, 87:182-191.

Mayer, R. E. (2005). Cognitive theory of multimedia learning. In The Cambridge handbook of multimedia learning. Cambridge University Press, NY.

Müller, U., Carpendale, J. I., and Smith, L. (2009). Introduction: Overview. the context of piaget's theory. In The Cambridge companion to Piaget, pages 1-44. Cambridge University Press.

OECD (2017). Programme for international student assessment - pisa 2015 - brazil.

Papert, S. and Harel, I. (1991). Situating constructionism. In Constructionism, volume 36, pages $1-11$.

Schiefele, U., Schaffner, E., Möller, J., and Wigfield, A. (2012). Dimensions of reading motivation and their relation to reading behavior and competence. Reading Research Quarterly, 47(4):427-463.

Seabra, A. G. and Capovilla, F. C. (2013). Prova de consciência fonológica por produção oral. In Avaliação Neuropsicológica Cognitiva, chapter 13. São Paulo: Memnon.

Sweller, J. (1994). Cognitive load theory, learning difficulty, and instructional design. Learning and instruction, 4(4):295-312.

Takacs, Z. K., Swart, E. K., and Bus, A. G. (2015). Benefits and pitfalls of multimedia and interactive features in technology-enhanced storybooks a meta-analysis. Review of educational research, 85(4):698-739. 